Research Paper

\title{
Prognostic Value of Ferritin-to-Hemoglobin Ratio in Patients with Advanced Non-Small-Cell Lung Cancer
}

\author{
Sookyung Lee ${ }^{1 凶}$, Hyeonjin Jeon², Bumsang Shim ${ }^{3}$ \\ 1. Department of Clinical Oncology, College of Korean Medicine, Kyung Hee University \\ 2. Department of Clinical Korean Medicine, Graduate School, Kyung Hee University \\ 3. Department of Pathology, College of Korean Medicine, Kyung Hee University \\ $\triangle$ Corresponding author: sookyung@khu.ac.kr \\ (c) Ivyspring International Publisher. This is an open access article distributed under the terms of the Creative Commons Attribution (CC BY-NC) license \\ (https://creativecommons.org/licenses/by-nc/4.0/). See http://ivyspring.com/terms for full terms and conditions.
}

Received: 2018.04.24; Accepted: 2019.01.20; Published: 2019.04.05

\begin{abstract}
Background: Among commonly used biomarkers that reflect overall health in patients with cancer, hemoglobin is an iron-containing, oxygen-carrying protein in red blood cells, and serum ferritin is an iron-storage protein. This study investigated the ability of the ferritin-to-hemoglobin ratio to predict survival in patients with advanced non-small-cell lung cancer (NSCLC).

Methods: The medical records of patients with pathologically confirmed advanced NSCLC were retrospectively reviewed. The ferritin level, hemoglobin level, and ferritin-to-hemoglobin ratio at the initiation of treatment were investigated. After descriptive analysis of the ferritin-to-hemoglobin ratio, the optimal diagnostic cutoff value for survival was determined using receiver operating characteristic analysis. After dichotomizing patients according to the optimal cutoff value, the prognostic effect of the ferritin-to-hemoglobin ratio was assessed. Overall survival (OS) was calculated using Kaplan-Meier analysis and compared using log-rank tests. Cox proportional hazards regression was used to evaluate the prognostic effect with respect to survival.

Results: Of the enrolled patients, $91.3 \%$ had stage IV NSCLC, $42.0 \%$ had an Eastern Cooperative Oncology Group-performance status (ECOG-PS) score of 2, and 56.5\% previously underwent systemic chemotherapy. The median OS of enrolled patients was 11.5 months. The range of the ferritin-to-hemoglobin ratio was $0.6-294.2$, and the optimal cutoff value of the ferritin-to-hemoglobin ratio for survival was 13.0 (sensitivity, 58.5\%; specificity, $80.0 \%$; area under the curve $=0.68 ; P=0.004$ ). The median OS of patients with a low ferritin-to-hemoglobin ratio $(<13.0)$ was 19.7 months, whereas that of patients with a high ferritin-to-hemoglobin ratio $(\geq 13.0)$ was 8.5 months $(P<0.001)$. After eliminating confounding factors such as age, sex, ECOG-PS, histologic type, and C-reactive protein level, a high ferritin-to-hemoglobin ratio was significantly associated with poor survival. The multivariate proportional hazards model revealed that the ferritin-to-hemoglobin ratio was an independent prognostic marker for survival (hazard ratio, 1.91; 95\% confidence interval, 1.27-2.88; $P=0.002$ ).

Conclusion: The ferritin-to-hemoglobin ratio, a potential parameter of tumor progression, was a significant prognostic factor for OS, with a direct correlation to survival time in patients with advanced NSCLC.
\end{abstract}

Key words: non-small cell lung cancer, prognosis, survival, ferritin, hemoglobinn

\section{Introduction}

Globally, lung cancer is the leading cause of cancer death.[1] Non-small-cell lung cancer (NSCLC), which is usually diagnosed at an advanced stage, accounts for the majority of lung cancer cases. In a clinical setting, an accurate prognosis is essential to determine treatment modalities and to manage patients with advanced NSCLC. To date, the prognosis of advanced NSCLC has been reported to be closely related to tumor progression, which is usually assessed in practice based on tumor response 
to therapy.

Along with tumor progression, anemia is one of the most frequently observed symptoms associated with solid tumors as well as hematologic malignancies. Anemia is a condition of insufficient oxygen-carrying capacity, defined as a low level of hemoglobin in the blood. Although the prevalence of anemia in patients with cancer has been reported to range from $30 \%$ to $77 \%$,[2] few studies have reported the effect of anemia on survival. Furthermore, the association of anemia with survival outcome remains controversial. In patients with NSCLC, there have been conflicting reports on the relationship between hemoglobin level and survival duration.[3-7]

Ferritin was originally identified as an iron-storage protein, which acts as a buffer for iron balance, and the level of ferritin is used as a diagnostic parameter for iron-deficiency anemia. As hyperferritinemia has been reported in cancer patients,[8] serum ferritin has been suggested as a tumor marker in the diagnosis of malignancies.[9] Recent studies have demonstrated that serum ferritin is a multifunctional protein, with antioxidant, ant-inflammatory, and anticarcinogenic roles, in addition to its role in iron storage.[10] An elevated serum ferritin level is reportedly associated with pathologic immunosuppression, proliferation, and angiogenesis, and could be an indicator of malignant disease.[11] In clinical studies, the serum ferritin level has been correlated with the response rate to platinum-based chemotherapy in patients with advanced NSCLC,[12] and an elevated serum ferritin level was an independent prognostic factor for a poor survival outcome in patients with advanced NSCLC.[13] Regarding the mechanism in cancer, a study reported that elevated serum ferritin is the result of inflammation and oxidative stress rather than iron overload.[14] High levels of ferritin and superoxide dismutase in the exhaled breath condensate of patients with NSCLC were associated with decreased survival time.[15]

Both hemoglobin and ferritin are iron-associated proteins in the blood. Hemoglobin carries oxygen, which is bound to the iron ion-coordinated heme component in body tissues, and ferritin is the major iron-binding protein that stores and releases iron in tissues. We previously reported the prognostic significance of serum ferritin in patients with advanced NSCLC compared with other host-related biomarkers.[13] Based on clinical experience, we identified that serum ferritin level was inversely correlated with hemoglobin level. As the tumor progressed in patients with advanced NSCLC, we observed that the serum ferritin level increased as the hemoglobin level decreased. Consequently, we investigated the relationship among hemoglobin, ferritin, and overall survival (OS) in advanced NSCLC. The research question from these observations was whether the ratio of ferritin-to-hemoglobin can predict the prognosis of advanced NSCLC. Therefore, this study aimed to investigate the prognostic significance of the ferritin-to-hemoglobin ratio for survival in patients with advanced NSCLC.

This is the first study to investigate the prognostic utility of the ferritin-to-hemoglobin ratio in patients with cancer. If the ferritin-to-hemoglobin ratio proves to be useful for predicting prognoses, it will facilitate the classification of patients according to their prognoses and allow for the identification of more appropriate treatment modalities. To manage patients with advanced cancer in clinical practice, a decision on appropriate treatment modalities increases the effectiveness of the treatment and allows patients to improve their quality of life. Therefore, as a first step toward identifying new prognostic factors, this study examined the prognostic significance of the ferritin-to-hemoglobin ratio for survival in patients with advanced NSCLC.

\section{Methods}

This retrospective review of the medical records of patients with advanced NSCLC was approved by the Institutional Review Board of Kyung Hee University Hospital at Gangdong (KHNMC-OH-IRB 2017-12005).

\section{Eligibility}

Patients with pathologically confirmed advanced NSCLC who were older than 18 years were included. Advanced NSCLC was defined as stage IIIB and IV based on the classification by the American Joint Committee on Cancer, $7^{\text {th }}$ edition.[16] Patients with Eastern Cooperative Oncology Group-performance status (ECOG-PS) scores of 0-2 who underwent laboratory tests at the initiation of treatment were enrolled. Those with brain metastasis were also included.

Patients who did not undergo laboratory tests at the initiation of treatment and those who were concurrently undergoing any conventional cancer therapy, such as chemotherapy or radiotherapy, were excluded. In addition, patients who underwent chemotherapy or radiotherapy 3 weeks before the time of the baseline laboratory tests were also excluded to eliminate the confounding effects of conventional cancer therapy. Patients with inadequate liver or renal function as revealed by abnormal levels of aspartate transaminase, alanine aminotransferase, total bilirubin, blood urea nitrogen, and creatinine and patients supported with supplemental oxygen were also excluded. Patients who were at a high risk 
of oncologic emergencies, such as superior vena cava syndrome and cardiac tamponade, were not eligible for this study.

\section{Variables}

ECOG-PS score, histologic type, tumor stage, the presence of metastasis, and hemoglobin, ferritin, C-reactive protein (CRP), and other biologic marker levels were investigated. The continuous variable prognostic factors were dichotomized based on cutoff values. Age was dichotomized with 65 years set as the criterion for elderly patients. The CRP cutoff level was $10 \mathrm{mg} / \mathrm{L}$, based on the criteria for inflammation scores. The hemoglobin cutoff levels were $12 \mathrm{~g} / \mathrm{dL}$ for women and $13 \mathrm{~g} / \mathrm{dL}$ for men, which are the cutoff values used in anemia studies.[17] The serum ferritin cutoff values were $200 \mathrm{ng} / \mathrm{mL}$ in men and $150 \mathrm{ng} / \mathrm{mL}$ in women, which indicate a severe risk of iron overload according to the serum ferritin guidelines of the World Health Organization.[18] The optimal cutoff value of the ferritin-to-hemoglobin ratio for survival was determined using receiver operating characteristics (ROC) analysis to maximize sensitivity and specificity.

\section{Management}

Patients were managed with Korean medicine $(\mathrm{KM})$, including herbal medicines and acupuncture. In this study, Rhus verniciflua Stokes (RVS) extract was used as the main anticancer agent. RVS, known as the lacquer tree in East Asia, has been reported to have apoptotic, antiproliferative, antiangiogenic, and antitumor migration effects on various cancer types.[19-23] Despite the anticancer effect of RVS, the use of RVS has been limited owing to the presence of urushiol, a toxic allergen. After removing the urushiol, the RVS extract was obtained through a standardized method and then concentrated and lyophilized into a powdered form. The major compounds in the final RVS extract were examined and quantified to ensure the absence of urushiol and to maintain consistent quality. The RVS extract was administered orally in a 500-mg capsule formulation. Three capsules containing a total of $1500 \mathrm{mg}$ of RVS extract were used as a daily dose.

In terms of clinical use, the RVS extract has prolonged OS in patients with advanced NSCLC when used concurrently with first-line chemotherapy, as maintenance therapy after first-line chemotherapy, and as a second-line treatment.[24, 25]

\section{Overall survival}

In this study, OS was defined as the period from the first day of KM management to the date of death from any cause. When patients were lost to follow-up or if death was not recorded, the patient was regarded as censored. The survival time of censored patients was defined as the period from KM management initiation to the last day of follow-up at the clinic.

\section{Statistical Analysis}

Clinicopathologic characteristics of enrolled patients were analyzed using descriptive analysis. Survival time was estimated using Kaplan-Meier survival curves and compared with log-rank tests. Cox proportional hazards regression was used to identify the prognostic effect for survival. The prognostic effect of the ferritin-to-hemoglobin ratio was assessed after controlling for confounding factors that may influence survival and that showed a relationship with the ferritin-to-hemoglobin ratio. Multivariate modeling was performed using full models with high-priority factors to avoid bias caused by overlapping factors. Subgroup analysis according to the ferritin-to-hemoglobin ratio was performed using a chi-square test to identify the characteristics of patients. The relationship between the ferritin-tohemoglobin ratio and other biomarkers was analyzed using correlation analysis. Statistical analyses were conducted using SAS E-guide version 4.2 software (SAS Institute, Cary, NC), and the figures of the ROC and Kaplan-Meier survival curves were modified using MedCalc statistical software version 17.7 (MedCalc Software Bvba, Ostend, Belgium).

\section{Results}

The clinicopathologic characteristics and biologic markers of 138 patients who met the eligibility criteria (Figure 1) are summarized in Table 1. Of the 138 enrolled patients, $79(57.3 \%)$ were men, and $59(42.8 \%)$ were older than 65 years. The majority of patients (126 [91.3\%]) had stage IV disease and had more than one organ with metastasis. Fifty-eight patients (42\%) had an ECOG-PS of 2. Adenocarcinoma and squamous cell carcinoma accounted for $68.1 \%$ and $21.0 \%$ of cases, respectively. Seventy-eight patients (56.5\%) previously underwent at least one chemotherapy regimen, and 60 patients (43.5\%) were chemotherapynaïve. The median time to initiate $\mathrm{KM}$ management was 4.8 months after the initial NSCLC diagnosis and 3.5 months after a metastatic NSCLC diagnosis.

The median hemoglobin level was 11.9 (range, 6.8-14.9) $\mathrm{g} / \mathrm{dL}$, the median serum ferritin level was 180.7 (range, 6.2-3118.5) $\mathrm{ng} / \mathrm{mL}$, and the median ferritin-to-hemoglobin ratio was 14.5 (range, 0.6-294.2). The correlation analysis revealed that hemoglobin and ferritin had a weakly negative relationship ( $r=-0.26 ; P=0.002$ ).

The optimal cutoff value for the ferritin-tohemoglobin ratio was 13 , with a sensitivity of $58.5 \%$ and a specificity of $80 \%$ (area under the curve, 0.68 ; $P$ 
$=0.004$; Figure 2). The median OS of the enrolled patients was 11.5 months (95\% confidence interval [CI], 10.7-14.8 months). In the comparison of the survival between dichotomized groups according to the cutoff value of the ferritin-to-hemoglobin ratio, the low ferritin-to-hemoglobin ratio group showed a significant prolongation of survival time (19.7 vs. 8.5 months; $P<0.001$; Figure 3).

To identify the prognostic factors associated with the ferritin-to-hemoglobin ratio, correlation analysis was performed with other potential prognostic factors. Among other factors, CRP, an indicator of systemic inflammation, was significantly correlated with the ferritin-to-hemoglobin ratio, showing a moderate positive relationship $(r=0.62, P<0.001)$.

Cox proportional hazards regression was performed to identify the predictive markers for survival. Among the clinicopathologic factors, age $\geq 65$ years (hazard ratio [HR], 1.64; 95\% CI, 1.14-2.35; $P=$ 0.008), poor ECOG-PS (HR, 2.01; 95\% CI, 1.40-2.88; $P<$ $0.001)$, and increased number of organs with metastasis (HR, 1.89; 95\% CI, 1.3-2.73; $P<0.001$ ) were associated with a significantly worse survival outcome. Regarding the biomarkers, patients with an elevated CRP level (HR, 2.54; 95\% CI, 1.76-3.68; $P<$ $0.001)$ or increased ferritin level (HR, 1.91; 95\% CI,
1.33-2.73; $P<0.001$ ) showed significantly poorer survival outcomes. In contrast, an elevated hemoglobin level (HR, 0.69; 95\% CI, 0.48-0.99; $P=$ 0.045) showed favorable survival outcomes. An increased serum ferritin-to-hemoglobin ratio was associated with significantly worse survival (HR, 2.19; 95\% CI, 1.52-3.16; $P<0.001$; Table 2).

Considering the influence of confounding factors on survival, multivariate analysis was performed after controlling for age, ECOG-PS, number of organs with metastasis, and CRP. In this analysis, age $\geq 65$ years (HR, 2.03; 95\% CI, 1.38-2.98; $P<0.001)$, increased CRP level (HR, 1.95; 95\% CI, 1.30-2.93; $P=0.001)$, and an elevated ferritin-to-hemoglobin ratio (HR, 1.94; 95\% CI, 1.29-2.91; $P=0.002$ ) were significantly associated with a poor survival outcome as independent prognostic factors for survival (Table 2).

A subgroup analysis according to the ferritin-tohemoglobin ratio was performed to compare the differences in other factors. The high ferritin-tohemoglobin ratio group had a significantly larger proportion of male patients $(P=0.036)$, and a high ferritin-to-hemoglobin ratio was associated with poor ECOG-PS $(P<0.001)$, an increased number of organs with metastasis $(P=0.001)$, and an elevated CRP level $(P<0.001)$ (Table 3$)$.

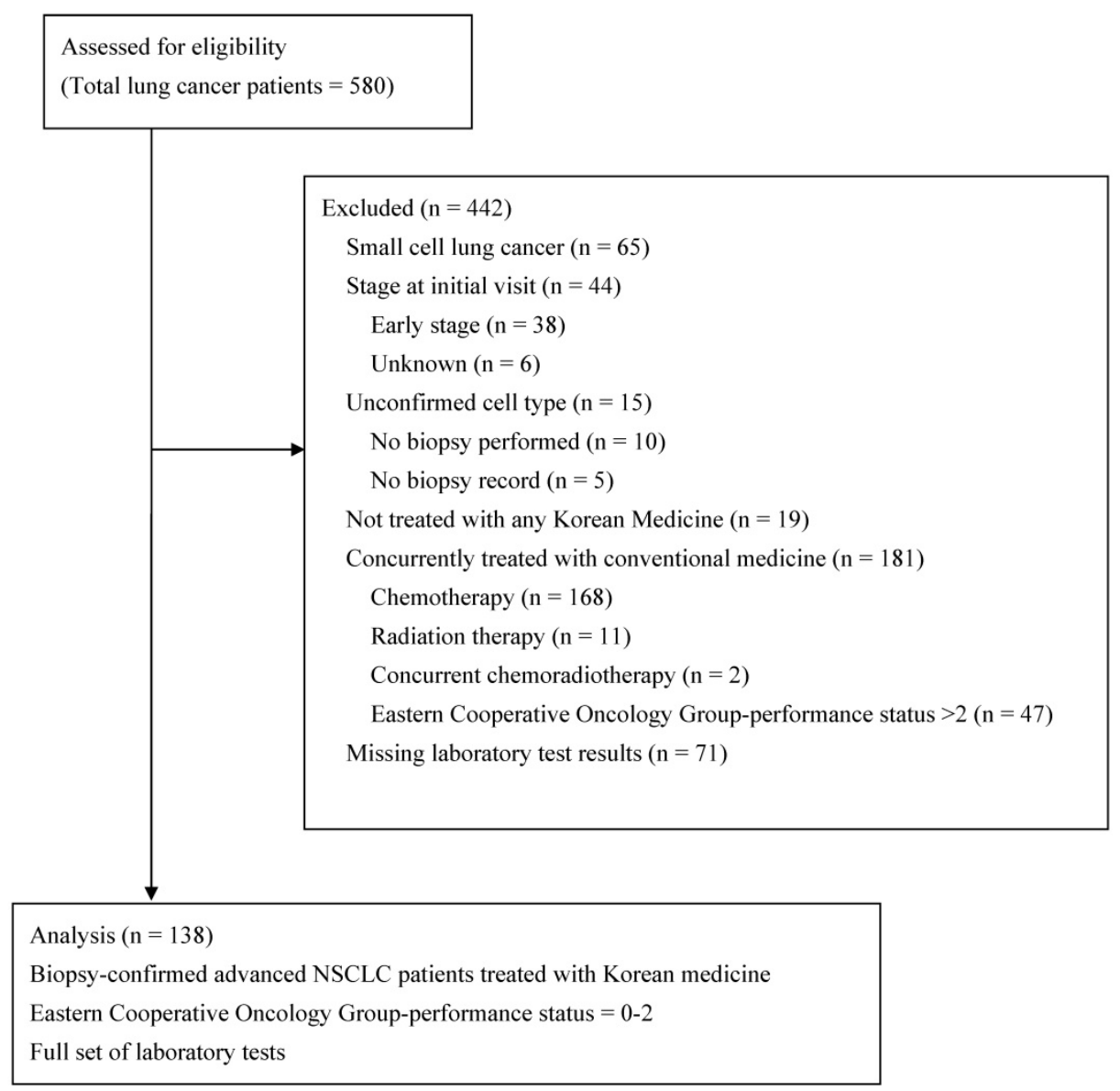

Figure 1. Flow diagram of the enrolled patients. 


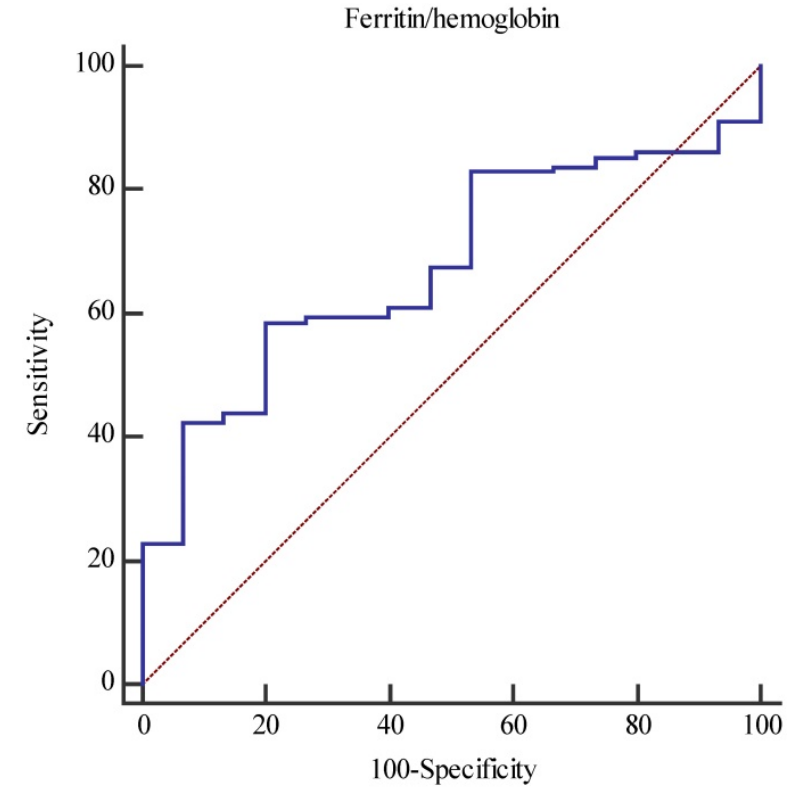

Figure 2. Receiver operating characteristic curve for the optimal cutoff value of the ferritin-to-hemoglobin ratio (sensitivity, $58.5 \%$; specificity, $80 \%$; area under the curve, 0.68; $P$-value, 0.004).

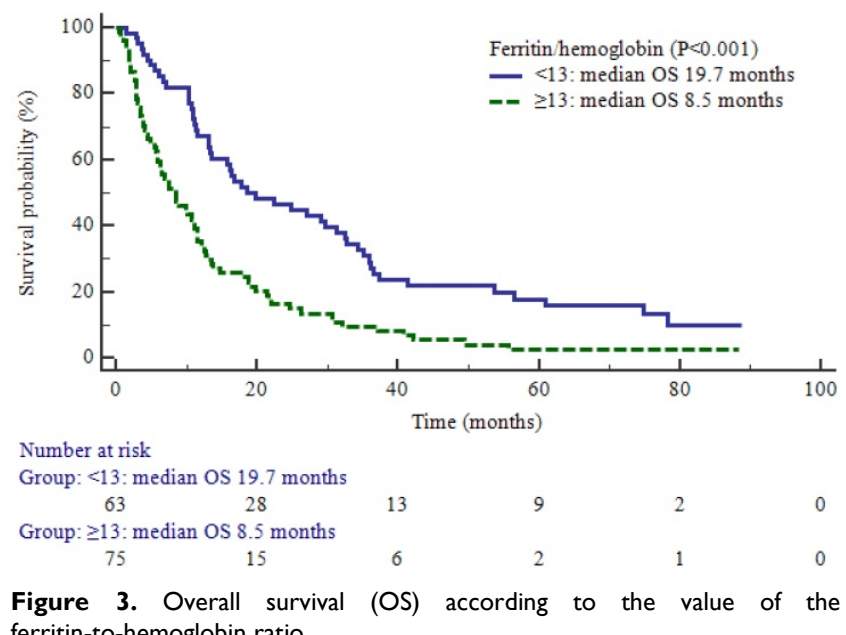

\section{Discussion}

The results of this study led to several interesting observations. In terms of the anatomical extent of tumor, the distinction between OS time of stage IIIB and IV advanced NSCLC was not significant, whereas the number of organs with metastasis had a significant effect on survival. However, as the number of stage IIIB cases in the present study were relatively low compared to the number of stage IV cases, we are unable to conclusively state that tumor-nodemetastasis staging did not affect OS. Our results are consistent with the recent classification of distant metastasis into a single extrathoracic metastasis and multiple extrathoracic metastases by the classification of stage IV lung cancer.[26]
Histologic tumor type has been reported as a significant prognostic factor for survival in patients before initiating first-line therapy after diagnosis of advanced NSCLC. Squamous cell carcinoma has been associated with an unfavorable survival outcome.[27] In this study, the histologic distinction of squamous and non-squamous NSCLC did not reveal a difference in survival outcome. This result may be due to the characteristics of the enrolled patients; $29 \%$ had previously undergone multiple lines of systemic therapy, which implies the presence of refractory cancer. Therefore, histological subtype may not affect the outcome of KM treatment, unlike that of systemic chemotherapy.

Table 1. Characteristics of the enrolled patients

\begin{tabular}{|c|c|}
\hline Variables & $\mathbf{N}(\%)$ \\
\hline \multicolumn{2}{|l|}{ Clinicopathologic factors } \\
\hline \multicolumn{2}{|l|}{ Age (years) } \\
\hline$<65$ & $82(59.4)$ \\
\hline$\geq 65$ & $56(40.6)$ \\
\hline \multicolumn{2}{|l|}{ Sex } \\
\hline Men & $79(57.3)$ \\
\hline Women & $59(42.8)$ \\
\hline \multicolumn{2}{|l|}{ ECOG-PS } \\
\hline 0 & $8(5.8)$ \\
\hline 1 & $72(52.2)$ \\
\hline 2 & $58(42.0)$ \\
\hline \multicolumn{2}{|l|}{ Histologic type } \\
\hline Squamous cell carcinoma & $29(21.0)$ \\
\hline Adenocarcinoma & $94(68.1)$ \\
\hline other & $15(10.9)$ \\
\hline \multicolumn{2}{|l|}{ Stage } \\
\hline IIIB & $12(8.7)$ \\
\hline IV & $126(91.3)$ \\
\hline \multicolumn{2}{|c|}{ Number of organs with metastasis } \\
\hline 0 & $12(8.7)$ \\
\hline 1 & $55(39.9)$ \\
\hline$\geq 2$ & $71(51.4)$ \\
\hline \multicolumn{2}{|l|}{ Prior surgery } \\
\hline No & $104(75.4)$ \\
\hline Yes & $34(24.6)$ \\
\hline \multicolumn{2}{|l|}{ Prior chemotherapy } \\
\hline None & $60(43.5)$ \\
\hline 1st line & $38(27.5)$ \\
\hline 2nd line & $40(29)$ \\
\hline \multicolumn{2}{|l|}{ Prior radiotherapy } \\
\hline No & $87(63.0)$ \\
\hline Yes & $51(37.0)$ \\
\hline \multicolumn{2}{|l|}{ Biologic markers } \\
\hline $\mathrm{CRP}(\mathrm{mg} / \mathrm{L})$ & $4.1(0.1-252.8)^{*}$ \\
\hline$\leq 10$ & $81(58.7)$ \\
\hline$>10$ & $57(41.3)$ \\
\hline Hemoglobin $(\mathrm{g} / \mathrm{dL})$ & $11.9(6.8-14.9)$ \\
\hline Men $<13$, women $<12$ & $80(58.0)$ \\
\hline Men $\geq 13$, women $\geq 12$ & $58(42.0)$ \\
\hline Ferritin (ng/mL) & $180.7(6.2-3118.5)$ \\
\hline Men $\leq 200$, women $\leq 150$ & $69(50)$ \\
\hline Men $>200$, women $>150$ & $69(50)$ \\
\hline Ferritin/hemoglobin & $14.5(0.6-294.2)$ \\
\hline$<13$ & $63(45.7)$ \\
\hline$\geq 13$ & $75(54.3)$ \\
\hline
\end{tabular}

*Median (range). Abbreviations: CRP, C-reactive protein; ECOG-PS, Eastern Cooperative Oncology Group-performance status. 
Table 2. Prognostic effects of host-related biomarkers according to Cox proportional hazards regression analysis

\begin{tabular}{|c|c|c|c|c|c|c|}
\hline \multirow[t]{2}{*}{ Variable } & \multicolumn{3}{|c|}{ Univariate analysis } & \multicolumn{3}{|c|}{ Multivariate analysis } \\
\hline & HR & $95 \% \mathrm{CI}$ & $P$-value & HR & $95 \% \mathrm{CI}$ & $P$-value \\
\hline \multicolumn{7}{|l|}{ Clinicopathologic factors } \\
\hline \multicolumn{7}{|l|}{ Age (years) } \\
\hline$<65$ & 1 & & & 1 & & \\
\hline$\geq 65$ & 1.64 & $1.14-2.35$ & 0.008 & 2.03 & $1.38-2.98$ & $<0.001$ \\
\hline \multicolumn{7}{|l|}{ Sex } \\
\hline Men & 1 & & & & & \\
\hline Women & 0.73 & $0.51-1.04$ & 0.084 & & & \\
\hline \multicolumn{7}{|l|}{ ECOG-PS } \\
\hline $0-1$ & 1 & & & 1 & & \\
\hline 2 & 2.01 & $1.40-2.88$ & $<0.001$ & 1.37 & $0.93-2.02$ & 0.109 \\
\hline \multicolumn{7}{|l|}{ Histologic type } \\
\hline Squamous cell carcinoma & 1 & & & & & \\
\hline $\begin{array}{l}\text { Non-squamous cell } \\
\text { carcinoma }\end{array}$ & 0.69 & $0.45-1.08$ & 0.103 & & & \\
\hline \multicolumn{7}{|l|}{ Stage } \\
\hline IIIB & 1 & & & & & \\
\hline IV & 1.12 & $0.58-2.13$ & 0.74 & & & \\
\hline \multicolumn{7}{|l|}{ No. of organs with metastasis } \\
\hline $0-1$ & 1 & & & 1 & & \\
\hline$\geq 2$ & 1.89 & $1.31-2.73$ & $<0.001$ & 1.35 & $0.91-2.01$ & 0.133 \\
\hline \multicolumn{7}{|l|}{ Biomarkers } \\
\hline \multicolumn{7}{|l|}{$\mathrm{CRP}(\mathrm{mg} / \mathrm{L})$} \\
\hline$\leq 10$ & 1 & & & 1 & & \\
\hline$>10$ & 2.54 & $1.76-3.68$ & $<0.001$ & 1.95 & $1.30-2.93$ & 0.001 \\
\hline \multicolumn{7}{|l|}{ Hemoglobin (g/dL) } \\
\hline Men $<13$, women $<12$ & 1 & & & & & \\
\hline Men $\geq 13$, women $\geq 12$ & 0.69 & $0.48-0.99$ & 0.045 & & & \\
\hline \multicolumn{7}{|l|}{ Ferritin (ng/mL) } \\
\hline Men $\leq 200$, women $\leq 150$ & 1 & & & & & \\
\hline Men $>200$, women $>150$ & 1.91 & $1.33-2.73$ & $<0.001$ & & & \\
\hline \multicolumn{7}{|l|}{ Ferritin/hemoglobin } \\
\hline$<13$ & 1 & & & 1 & & \\
\hline$\geq 13$ & 2.19 & $1.52-3.16$ & $<0.001$ & 1.94 & $1.29-2.91$ & 0.002 \\
\hline
\end{tabular}

Table 3. Clinical characteristics according to the ferritin-tohemoglobin ratio

\begin{tabular}{|c|c|c|c|}
\hline Variables & $\begin{array}{l}\text { Ferritin/ } \\
\text { hemoglobin }<13 \\
(n=63)\end{array}$ & $\begin{array}{l}\text { Ferritin/ } \\
\text { hemoglobin } \geq 13 \\
(n=75)\end{array}$ & $\begin{array}{l}P- \\
\text { value }\end{array}$ \\
\hline Age (years) & & & 0.232 \\
\hline$<65$ & 34 & 48 & \\
\hline$\geq 65$ & 29 & 27 & \\
\hline Sex & & & 0.036 \\
\hline Men & 30 & 49 & \\
\hline Women & 33 & 26 & \\
\hline ECOG-PS & & & $<0.001$ \\
\hline $0-1$ & 48 & 32 & \\
\hline 2 & 15 & 43 & \\
\hline Histologic type & & & 0.92 \\
\hline Squamous cell carcinoma & 13 & 16 & \\
\hline Non-squamous cell carcinoma & 50 & 59 & \\
\hline Stage & & & 0.126 \\
\hline IIIB & 8 & 4 & \\
\hline IV & 55 & 71 & \\
\hline No. of organs with metastasis & & & 0.001 \\
\hline $0-1$ & 40 & 27 & \\
\hline$\geq 2$ & 23 & 48 & \\
\hline $\mathrm{CRP}(\mathrm{mg} / \mathrm{L})$ & & & $<0.001$ \\
\hline$\leq 10$ & 50 & 31 & \\
\hline$>10$ & 13 & 44 & \\
\hline
\end{tabular}

Group-performance status.
Hemoglobin, which transports oxygen bound to iron ions, is an important biomarker for anemia. Anemia has reportedly been diagnosed in more than $70 \%$ of patients with solid tumors as well as in patients with hematologic malignancies, indicating that it is affected by disease course or therapeutic procedures.[2] Cancer-related anemia is a multifactorial issue related to nutritional, metabolic, and immune components of cancer and is associated with the progress and severity of cancer.[28] Hemoglobin has not been directly implicated in tumor progression; therefore, the prognostic effect of hemoglobin for survival has been contradicted by several observational studies.[3-7]

In contrast, ferritin, an iron storage protein, has been found to be associated with cancer progression in a number of pathways since its association with cancer was first published in 1977.[8] Ferritin has been demonstrated to play a role in tumor progression through its relationship with macrophages, regulatory effect on angiogenesis, association with inflammation as an acute-phase protein, and relevance in oxidative stress.[29]

Ferritin is a 24-subunit protein composed of two types of subunits: ferritin heavy chain and ferritin light chain. The source of serum ferritin is still unclear; however, some studies reported that serum ferritin is secreted by hepatocytes and macrophages. [30] In particular, macrophages were revealed as a major cellular source of serum ferritin.[30, 31] Tumor-associated macrophages (TAMs) play a major role in tumor progression through direct mechanisms to secret procarcinogenic molecules and indirect mechanisms of iron binding and ferritin release.[32] TAM ferritin in the tumor microenvironment was shown to be an important element in promoting cancer cell proliferation and tumor growth in breast cancer.[31, 33] These findings that macrophages are an important cellular source of ferritin and that TAM is associated with ferritin may explain the significantly elevated level of serum ferritin in inflammatory conditions and the close relationship to the CRP level. This phenomenon is also consistent with the results of the correlation analysis of the present study, which showed that the ferritin-tohemoglobin ratio was significantly correlated to the CRP level with a moderate positive relationship. Therefore, further studies may reveal a functional link of serum ferritin that connects carcinogenesis and inflammation.

In terms of the regulatory effect on angiogenesis, ferritin promotes tumor angiogenesis by binding high molecular weight kininogen, thereby enhancing migration and tube formation.[29, 34] Regarding oxidative stress, ferritin is considered a surrogate 
marker for oxidative stress, and a high level of serum ferritin could accelerate the generation of reactive oxygen species or oxidative DNA damage in cells.[35] Studies also found that ferritin was associated with tumor suppressor p53 protein and that downregulation of ferritin increased the sensitivity of breast cancer cells to chemotherapy.[29] Moreover, increasing evidence of the relevance of ferritin to cancer through various mechanisms has been reported, such as the association with nuclear factor- $\mathrm{kB}$ signaling [36] and mitochondrial ferritin in tumor cells,[37-40] among others.

In a clinical study, the ferritin level of breast cancer tissue was six-fold higher than that in normal or benign breast tissue,[41] indicating that the level of ferritin can be used as an indicator or a prognostic biomarker of breast cancer.[33, 42, 43] In addition to breast cancer, the serum ferritin level has also been found to be elevated in patients with lung cancer, pancreatic cancer, hepatocellular carcinoma, colorectal cancer, leukemia, and lymphoma, and the level was closely associated with the prognosis.[13, 33, 43-51] We have also reported the prognostic effect of serum ferritin as a host-related biomarker for survival in patients with colon cancer and NSCLC.[13, 50] The reason we pay attention to the ferritin-to-hemoglobin ratio is that, as the cancer progresses, we frequently observe that the ferritin concentration increases while the hemoglobin level decreases. This phenomenon differs from iron-deficiency anemia in which ferritin and hemoglobin decrease simultaneously. Similarly, a large observational study reported that hemoglobin levels were inversely associated with ferritin levels in patients with lung cancer, which is different from that observed in patients with gastrointestinal cancers.[28] Based on these findings, we aimed to investigate the prognostic significance of the ferritin-to-hemoglobin ratio for survival in patients with advanced NSCLC.

Our results showed that the ferritin-to-hemoglobin ratio was an independent prognostic factor for predicting survival in patients with advanced NSCLC. As a prognostic factor, the ferritin-tohemoglobin ratio was comparable to that of the level of CRP, a well-known biomarker of systemic inflammation. As mentioned in previous studies, the main source of ferritin is macrophages, which means that ferritin is secreted by the host and not by the tumor. Thus, ferritin is a unique host-related biomarker that represents tumor burden. Therefore, both ferritin and hemoglobin are host-related factors that reflect the overall patient condition, implying multiple physiological and pathological processes. Hemoglobin is a biomarker routinely included in follow-up blood counts, and ferritin is a biomarker that provides information with respect to anemia and tumor progression.

The ferritin-to-hemoglobin ratio is calculated by dividing the ferritin level, which increases with tumor progression, by the hemoglobin level, which reflects the overall condition of the host. The ratio changes depending on the relationship between the tumor and the host. The ferritin-to-hemoglobin ratio maximizes the prognostic impact of ferritin and hemoglobin, and an increased ratio implies tumor progression, based on the results of this study. To validate the clinical interpretation of the ferritin-to-hemoglobin ratio, more studies on the pathophysiological roles related to the tumor and host are necessary.

In clinical practice, the individual levels of hemoglobin and ferritin may be used to predict survival by means of the ferritin-to-hemoglobin ratio, which can provide useful information for managing patients with advanced cancer. Additionally, there is an economic advantage to low-cost tests; therefore, the ferritin-to-hemoglobin ratio may be used in various clinical settings.

Considering that a high ferritin-to-hemoglobin ratio was associated with a poor ECOG-PS, multiple organ metastases, and increased CRP levels, and that the main source of ferritin is the macrophage involved in tumor progression, the ratio can be more useful to predict prognosis in patients with relapsed or refractory advanced cancer than in those with newly diagnosed early cancer. In clinical practice, the ferritin-to-hemoglobin ratio could be applied as a prognostic index to select appropriate treatment modalities for anticancer therapy such as palliative care or supportive care. The need for detailed distinctions in advanced cancer coincides with the recently revised classification of stage IVA and IVB according to single or multiple extrathoracic metastases, which was also intended to facilitate accurate prediction of prognosis and survival in lung cancer.[26, 52]

As a retrospective cohort study, this study has limitations in that a comparison of various variables, including hepcidin, transferrin, and iron, that may have potential associations with ferritin and hemoglobin were not measured.[32] The study population was also limited to patients who underwent KM treatment at a single institution. Therefore, to extrapolate our results to the clinical setting, prospective studies with various candidate variables are necessary. In addition, to provide a basis for the results observed in this clinical study, research on the pathophysiologic roles of ferritin and hemoglobin in cancer progression will be necessary for the understanding of their mechanism of action. Despite these limitations, considering that an observational study using existing resources is a powerful method 
to generate evidence to test new hypotheses, this is the first study to investigate the ferritin-tohemoglobin ratio, and the results contribute to the prediction of prognosis in patients with cancer.

\section{Acknowledgments}

We thank the patients and medical staff who managed the patients in practice.

\section{Source of support}

This study was supported by Kyung Hee University Hospital at Gangdong and Kyung Hee University.

\section{Competing Interests}

The authors have declared that no competing interest exists.

\section{References}

1. Global Burden of Disease Cancer C, Fitzmaurice C, Allen C, Barber RM, Barregard L, Bhutta ZA, et al. Global, Regional, and National Cancer Incidence, Mortality, Years of Life Lost, Years Lived With Disability, and Disability-Adjusted Life-years for 32 Cancer Groups, 1990 to 2015: A Systematic Analysis for the Global Burden of Disease Study. JAMA Oncol. 2017; 3: 524-48.

2. Weiss G, Goodnough LT. Anemia of chronic disease. The New England journal of medicine. 2005; 352: 1011-23.

3. Albain KS, Crowley JJ, LeBlanc M, Livingston RB. Survival determinants in extensive-stage non-small-cell lung cancer: the Southwest Oncology Group experience. J Clin Oncol. 1991; 9: 1618-26.

4. Gauthier I, Ding K, Winton T, Shepherd FA, Livingston R, Johnson DH, et al. Impact of hemoglobin levels on outcomes of adjuvant chemotherapy in resected non-small cell lung cancer: the JBR.10 trial experience. Lung cancer. 2007; 55: 357-63

5. MacRae R, Shyr Y, Johnson D, Choy H. Declining hemoglobin during chemoradiotherapy for locally advanced non-small cell lung cancer is significant. Radiotherapy and oncology : journal of the European Society for Therapeutic Radiology and Oncology. 2002; 64: 37-40.

6. Tomita M, Shimizu T, Hara M, Ayabe T, Onitsuka T. Impact of preoperative hemoglobin level on survival of non-small cell lung cancer patients. Anticancer Res. 2008; 28: 1947-50.

7. Jazieh AR, Hussain M, Howington JA, Spencer HJ, Husain M, Grismer JT, et al. Prognostic factors in patients with surgically resected stages I and II non-small cell lung cancer. Ann Thorac Surg. 2000; 70: 1168-71.

8. Hazard JT, Drysdale JW. Ferritinaemia in cancer. Nature. 1977; 265: 755-6.

9. Cazzola M, Arosio P, Bellotti V, Bergamaschi G, Dezza L, Iacobello C, et al. Immunological reactivity of serum ferritin in patients with malignancy. Tumori. 1985; 71: 547-54

10. Alkhateeb AA, Connor JR. The significance of ferritin in cancer: anti-oxidation, inflammation and tumorigenesis. Biochim Biophys Acta. 2013; 1836: 245-54.

11. Wang W, Knovich MA, Coffman LG, Torti FM, Torti SV. Serum ferritin: Past, present and future. Biochim Biophys Acta. 2010; 1800: 760-9.

12. Shi HB, Li XD, Jiang JT, Zhao WQ, Ji M, Wu CP. Serum ferritin is elevated in advanced non-small cell lung cancer patients and is associated with efficacy of platinum-based chemotherapy. J Cancer Res Ther. 2014; 10: 681-5.

13. Lee S, Eo W, Jeon H, Park S, Chae J. Prognostic Significance of Host-related Biomarkers for Survival in Patients with Advanced Non-Small Cell Lung Cancer. J Cancer. 2017; 8: 2974-83.

14. Kukulj S, Jaganjac M, Boranic M, Krizanac S, Santic Z, Poljak-Blazi M. Altered iron metabolism, inflammation, transferrin receptors, and ferritin expression in non-small-cell lung cancer. Med Oncol. 2010; 27: 268-77.

15. Carpagnano GE, Lacedonia D, Palladino GP, Koutelou A, Martinelli D, Orlando S, et al. Could exhaled ferritin and SOD be used as markers for lung cancer and prognosis prediction purposes? Eur J Clin Invest. 2012; 42: 478-86.

16. Goldstraw P, Crowley J, Chansky K, Giroux DJ, Groome PA, Rami-Porta R, et al. The IASLC Lung Cancer Staging Project: proposals for the revision of the TNM stage groupings in the forthcoming (seventh) edition of the TNM Classification of malignant tumours. Journal of thoracic oncology : official publication of the International Association for the Study of Lung Cancer. 2007; 2: 706-14.

17. WHO. Hemoglobin concentrations for the diagnosis of anaemia and assessment of severity. 2011.

18. WHO. Serum ferritin concentrations for the assessment of iron status and iron deficiency in populations. 2011.
19. Choi WC LJ, Lee EO, et al. Study on antiangiogenic and antitumor activities of processed Rhus Verniciflua Stokes extract. Korean J Oriental Physiology \& Pathology. 2006; 20: 1-5.

20. Kim JH, Kim HP, Jung $\mathrm{CH}$, Hong $\mathrm{MH}$, Hong MC, Bae HS, et al. Inhibition of cell cycle progression via p27Kip1 upregulation and apoptosis induction by an ethanol extract of Rhus verniciflua Stokes in AGS gastric cancer cells. Int J Mol Med. 2006; 18: 201-8

21. Lee SK, Jung HS, Eo WK, Lee SY, Kim SH, Shim BS. Rhus verniciflua Stokes extract as a potential option for treatment of metastatic renal cell carcinoma: report of two cases. Ann Oncol. 2010; 21: 1383-5.

22. Lee JH, Lee HJ, Lee HI, Choi WC, Yoon SW, Ko SG, et al. Rhus verniciflua Stokes prevents cisplatin-induced cytotoxicity and reactive oxygen species production in MDCK-I renal cells and intact mice. Phytomedicine international journal of phytotherapy and phytopharmacology. 2009; 16: 188-97.

23. Park JH, Moon G. Effect of allergen removed Rhus verniciflua extract on nhibition of tumor metastasis. J of Kor Traditional Oncology. 2010; 15: 47-61.

24. Lee J, Chae J, Lee S, Kim K, Eo W, Kim S, et al. The efficacy and safety of standardized allergen-removed Rhus verniciflua extract as maintenance therapy after first-line chemotherapy in patients with advanced non-small cell lung cancer. The American journal of Chinese medicine 2013 41:773-87.

25. Cheon SH, Kim KS, Kim S, Jung HS, Choi WC, Eo WK. Efficacy and safety of Rhus verniciflua stokes extracts in patients with previously treated advanced non-small cell lung cancer. Forschende Komplementarmedizin. 2011; 18: $77-83$

26. Detterbeck FC, Boffa DJ, Kim AW, Tanoue LT. The Eighth Edition Lung Cancer Stage Classification. Chest. 2017; 151: 193-203.

27. McKeage MJ, Jameson MB, Investigators ASSG. Comparative outcomes of squamous and non-squamous non-small cell lung cancer (NSCLC) patients in phase II studies of ASA404 (DMXAA) - retrospective analysis of pooled data. J Thorac Dis. 2010; 2: 199-204.

28. Maccio A, Madeddu C, Gramignano G, Mulas C, Tanca L, Cherchi MC, et al. The role of inflammation, iron, and nutritional status in cancer-related anemia: results of a large, prospective, observational study. Haematologica. 2015; 100: 124-32.

29. Torti SV, Torti FM. Iron and cancer: more ore to be mined. Nat Rev Cancer. 2013; 13: 342-55

30. Cohen LA, Gutierrez L, Weiss A, Leichtmann-Bardoogo Y, Zhang DL, Crooks $\mathrm{DR}$, et al. Serum ferritin is derived primarily from macrophages through a nonclassical secretory pathway. Blood. 2010; 116: 1574-84.

31. Alkhateeb AA, Han B, Connor JR. Ferritin stimulates breast cancer cells through an iron-independent mechanism and is localized within tumor-associated macrophages. Breast Cancer Res Treat. 2013; 137: 733-44.

32. Orlandi R, De Bortoli M, Ciniselli CM, Vaghi E, Caccia D, Garrisi V, et al. Hepcidin and ferritin blood level as noninvasive tools for predicting breast cancer. Ann Oncol. 2014; 25: 352-7.

33. Jezequel P, Campion L, Spyratos F, Loussouarn D, Campone M, Guerin-Charbonnel C, et al. Validation of tumor-associated macrophage ferritin light chain as a prognostic biomarker in node-negative breast cancer tumors: A multicentric 2004 national PHRC study. Int J Cancer. 2012; 131: 426-37.

34. Coffman LG, Parsonage D, D'Agostino R, Jr., Torti FM, Torti SV. Regulatory effects of ferritin on angiogenesis. Proc Natl Acad Sci U S A. 2009; 106: 570-5.

35. Kikuchi S, Kobune M, Iyama S, Sato T, Murase K, Kawano Y, et al. Prognostic significance of serum ferritin level at diagnosis in myelodysplastic syndrome. Int J Hematol. 2012; 95: 527-34.

36. Pham CG, Bubici C, Zazzeroni F, Papa S, Jones J, Alvarez K, et al. Ferritin heavy chain upregulation by NF-kappaB inhibits TNFalpha-induced apoptosis by suppressing reactive oxygen species. Cell. 2004; 119: 529-42.

37. Arosio P, Levi S. Cytosolic and mitochondrial ferritins in the regulation of cellular iron homeostasis and oxidative damage. Biochim Biophys Acta. 2010; 1800: 783-92.

38. Nie G, Sheftel AD, Kim SF, Ponka P. Overexpression of mitochondrial ferritin causes cytosolic iron depletion and changes cellular iron homeostasis. Blood. 2005; 105: 2161-7.

39. Santambrogio P, Erba BG, Campanella A, Cozzi A, Causarano V, Cremonesi L, et al. Over-expression of mitochondrial ferritin affects the JAK2/STAT5 pathway in K562 cells and causes mitochondrial iron accumulation. Haematologica. 2011; 96: 1424-32.

40. Shi ZH, Shi FF, Wang YQ, Sheftel AD, Nie G, Zhao YS, et al. Mitochondrial ferritin, a new target for inhibiting neuronal tumor cell proliferation. Cell Mol Life Sci. 2015; 72: 983-97.

41. Weinstein RE, Bond BH, Silberberg BK. Tissue ferritin concentration in carcinoma of the breast. Cancer. 1982; 50: 2406-9.

42. Marcus DM, Zinberg N. Measurement of serum ferritin by radioimmunoassay: results in normal individuals and patients with breast cancer. Journal of the National Cancer Institute. 1975; 55: 791-5.

43. Weinstein RE, Bond BH, Silberberg BK, Vaughn CB, Subbaiah P, Pieper DR. Tissue ferritin concentration and prognosis in carcinoma of the breast. Breast Cancer Res Treat. 1989; 14: 349-53.

44. Xiong W, Wang L, Yu F. Regulation of cellular iron metabolism and its implications in lung cancer progression. Med Oncol. 2014; 31: 28.

45. Kalousova M, Krechler T, Jachymova M, Kubena AA, Zak A, Zima T. Ferritin as an independent mortality predictor in patients with pancreas cancer. Results of a pilot study. Tumour Biol. 2012; 33: 1695-700. 
46. Facciorusso A, Del Prete V, Antonino M, Neve V, Crucinio N, Di Leo A, et al. Serum ferritin as a new prognostic factor in hepatocellular carcinoma patients treated with radiofrequency ablation. J Gastroenterol Hepatol. 2014; 29: 1905-10.

47. Zhang XZ, Su AL, Hu MQ, Zhang XQ, Xu YL. Elevated serum ferritin levels in patients with hematologic malignancies. Asian Pac J Cancer Prev. 2014; 15: 6099-101.

48. Yoh KA, Lee HS, Park LC, Lee EM, Shin SH, Park DJ, et al. The prognostic significance of elevated levels of serum ferritin before chemotherapy in patients with non-Hodgkin lymphoma. Clin Lymphoma Myeloma Leuk. 2014; 14: 43-9.

49. Yamazaki E, Tomita N, Koyama S, Ogusa E, Ishii Y, Takahashi H, et al. Serum ferritin level is prognostic of patient outcome in extranodal NK/T cell lymphoma, nasal type. Med Oncol. 2014; 31: 149.

50. Lee S, Song A, Eo W. Serum Ferritin as a Prognostic Biomarker for Survival in Relapsed or Refractory Metastatic Colorectal Cancer. J Cancer. 2016; 7: 957-64.

51. Milman N, Pedersen LM. The serum ferritin concentration is a significant prognostic indicator of survival in primary lung cancer. Oncol Rep. 2002; 9: 193-8.

52. Goldstraw P, Chansky K, Crowley J, Rami-Porta R, Asamura H, Eberhardt WE, et al. The IASLC Lung Cancer Staging Project: Proposals for Revision of the TNM Stage Groupings in the Forthcoming (Eighth) Edition of the TNM Classification for Lung Cancer. Journal of thoracic oncology : official publication of the International Association for the Study of Lung Cancer. 2016; 11: 39-51. 